\title{
HYGROSCOPIC EXPANSION OF SOME CASTING INVESTMENTS
}

\author{
N. I,ANDGREN, D.D.S., M.S., AND F. A. PEYTON, D.Sc. \\ School of Dentistry, University of Michigan, Ann Arbor, Mich.
}

CREDIT is generally given to Taggart ${ }^{1}$ for introducing the cast gold inlay to the dental profession. Although he realized that gold shrinks when cooled from molten state to solid state of room temperature, the investment available to him did not supply sufficient compensation. In 1910, Van Horn ${ }^{2}$ published a paper dealing with a method by which he obtained the compensation by means of wax expansion. The next major research in connection with this problem was the work of Coleman ${ }^{3}$ at the National Bureau of Standards. He determined the gold shrinkage to be 1.25 per cent and presented a casting technic with compensation values of quantitative nature. The total compensation for the gold shrinkage was obtained by the combination of the setting and thermal expansion of the mold. This procedure is the general practice followed at the present time for compensation.

There are some disadvantages to this method. Skinner has indicated the difficulty of obtaining smooth castings and the improper compensation for the casting shrinkage. ${ }^{4}$ It has been found by Hollenback ${ }^{5}$ and Scheu ${ }^{6 a}$ that castings made at a high temperature are rougher than those made at a low temperature $\left(450^{\circ}\right.$ C.), depending upon the great difference in thermal expansion between plaster of Paris and silica, which causes a poor union of the fine particles. This may also result in friability and there may be some warpage due to the differential expansion. A method which provides sufficient compensation at a low mold temperature is the hygroseopic casting technic. ${ }^{6 \mathrm{~b}}$

Wilson ${ }^{7}$ showed that certain plasters expand as much as 0.0044 inch to the inch by taking up moisture from the air. With this information at hand, Scheu ${ }^{6 a, b}$ tested some commercial investment to determine what results the addition of moisture would have. He found ${ }^{6 b}$ : (1) All of the casting investments that were tested expanded. (2) The thicker the mix, the greater the expansion. (3) A mix with hot water expanded more than one with cold water. (4) The time at which the mix is placed in the water is of great importance. It was found that if the mix is placed in the water early, it would not expand so much as when placed in a little later. It was also found that if the mix was placed in the water after a certain time, it could not expand to the maximal amount. (5) The temperature of the water in which the mix is placed is important, for two reasons; (a) the temperature of the water controls slightly the expansion of the investment, and (b) water at a temperature of $100^{\circ} \mathrm{F}$. slightly softens the wax pattern so that the fine margins are not marred while expansion is taking place. The mix should remain in the water at least 20 minutes to obtain the full expansion, after which time no further expansion is obtained.

Presented at the Materials Group Session of the Twenty-seventh General Meeting of the International Association for Dental Research, Chicago, June $24-26,1949 . \quad$ (J. D. Res. 27:
$665,1949$.

Received for publication, November 18, 1949. 
Docking ${ }^{8}$ found that both a high silica content and fine silica particles gave increased hygroscopic expansion. The use of plaster of Paris instead of hydrocal reduces the hygroscopic expansion to such an extent that mixtures of plaster and silica may be unsuitable to this new technic. Both a thick mix and warm water give increased expansion. Like normal setting expansion, the hygroscopic type is very sensitive to restrictive forces such as those provided by the interior surface of the ring or by a tightly packed lining. The amount of water taken up will affect the ultimate expansion and to get full expansion the invested pattern is completely immersed in water and left for a period of time. According to Docking, most of the expansion takes place in the first 10 to 12 minutes and there is little further expansion after about 45 minutes. The temperature of the bath was maintained at $100^{\circ} \mathrm{F}$., which eliminates the need for compensation of shrinkage of the wax pattern from oral to room temperature. This temperature also helps to soften the wax slightly in order to reduce its interference with the expansion. With regard to the temperature of the bath, Docking observed the same result as Scheu. According to Docking, "The hygroscopic technique is recommended for general use only if a thorough study is first made of it in relation to the particular investment to be applied."'

In his investigation, Degni ${ }^{9}$ found that hygroseopic expansion is very sensitive to confinement of any kind. He also found that the greater the amount of hydrocal in the investment, the less will be the hygroscopic expansion. While the mechanism of hygroscopic expansion is not completely known, a colloidal theory for the setting of plaster of Paris is frequently advanced, ${ }^{10}$ and Degni used this to explain hygroscopic expansion.

\section{METHODS FOR MEASURING EXPANSION}

Several methods have been used for measuring hygroscopic expansion. Coleman, ${ }^{11}$ at the Bureau of Standards, used a V-shaped support for the investment and two micrometer microscopes attached to a common base. The investment was mixed and poured into the $\mathrm{V}$-shaped support, which was lined with waxed paper to prevent the investment from adhering to its walls. A small metal plate was placed at each end of the sample. The micrometer microscopes were focused on reference lines which were ruled on the plates and the length change between the reference lines were measured with the microscope. Although Coleman used this method to measure normal setting expansion, it has been used later by some investigators to study hygroscopic expansion.

In Scheu's experiments, a mix of investment was placed in a rectangular mold formed with precision gauge blocks on a glass slab. The investment with gauge block mold was immersed in water after the initial set.

Docking ${ }^{8}$ used an entirely different method where he allowed the investment to float in a bath of mercury. Here the specimen was quite free to expand or contract against practically no external forces. After addition of water, readings are made with a micrometer microscope focused on a needle placed in the investment. In a later study Docking used a modification of the inlay ring method employed by Degni. 
Degni reported having made a number of trials with the Coleman method but could not obtain the values reported by Scheu (1.6 per cent) and abandoned the metal trough as unsuitable for measuring hygroseopic expansion depending upon the friction between the liners in the metal trough and the investment. He then applied a dial gauge method. A glass bowl with electrically heated water was used. The specimen was prepared in a casting ring with wet asbestos lining. A thin glass plate, made from a portion of a microscope cover slide, was placed on the top of the specimen. A dial gauge graduated in $0.01 \mathrm{~mm}$. was applied on the glass slide and readings were taken each minute. Some of the specimens were prepared in a wax ring which were withdrawn when the mix had thickened sufficiently and the specimen was immersed in water. The hygroscopic expansion could be measured in that way. Watts ${ }^{12}$ used the dial gauge method in determining the hygroscopic expansion due to one layer of wet asbestos, which he found to be 0.16 per cent.

After studying the results obtained by different investigators, it is evident that they vary with the method of measuring. With the mercury bath, Docking measured the dimensional changes which take place while the mixture is still semifluid and adaptable. "These would be normally taken up as volume changes in the mix which in the initial stages is too weak to expand or compress a wax pattern or otherwise to alter the dimension of the cavity occupied by the pattern. Any expanding forces, for instance, attempting to draw the investment away from the pattern, will be insufficient to overeome the action of gravity which forces the semifluid mix to conform to the contours of the wax. From the practical point of view, therefore, it is the expansion after the mix has set enough to support itself that is important." at which this condition occurs is obscure. The setting time obtained by a Gillmore needle is not necessarily the time at which the investment will show effective expansion. The arbitrary nature of setting time and expansion determination must, therefore, always be kept in mind. In his work with determination of normal setting expansion of investments, Skinner ${ }^{13}$ has stated that any changes in dimension before the initial set are of no practical importance, but that is not necessarily true in the hygroscopic expansion of the investments.

\section{PURPOSE AND METHOD OF MEASUREMENT}

The purpose of this investigation was to study the hygroscopic expansion of some of the investments generally in use at the present time. It was desired to study them under conditions most nearly approaching those occurring in dental practice; therefore, the dial gauge method of Degni was chosen, where the specimen is prepared in a casting ring with wet asbestos lining. A weighed quantity of investment powder was added to a measured amount of distilled water at room temperature in the mixing bowl. The mix was then spatulated by hand for 30 seconds and poured into the casting ring lined with wet asbestos. On top of the ring a microscope cover slide was placed with a length equal to the diameter of the ring. The specimen was then placed in a water bath kept at a constant temperature $\left( \pm 2^{\circ} \mathrm{F}\right.$.) by means of a Bunsen burner, and the 
temperature was observed by a thermometer inserted in the bath. The expansion of the specimen was measured by the dial micrometer placed in contact with the microscope cover slide on top of the specimen. In order to reduce the pressure of the dial gauge on the specimen, the dial gauge was counterbalanced. A thread was attached to the head of the gauge spindle and then passed over a pulley with a weight of $36 \mathrm{Gm}$. suspended at its free end. The apparatus is shown in Fig. 1. The test samples had an initial length of 1.493 inches.

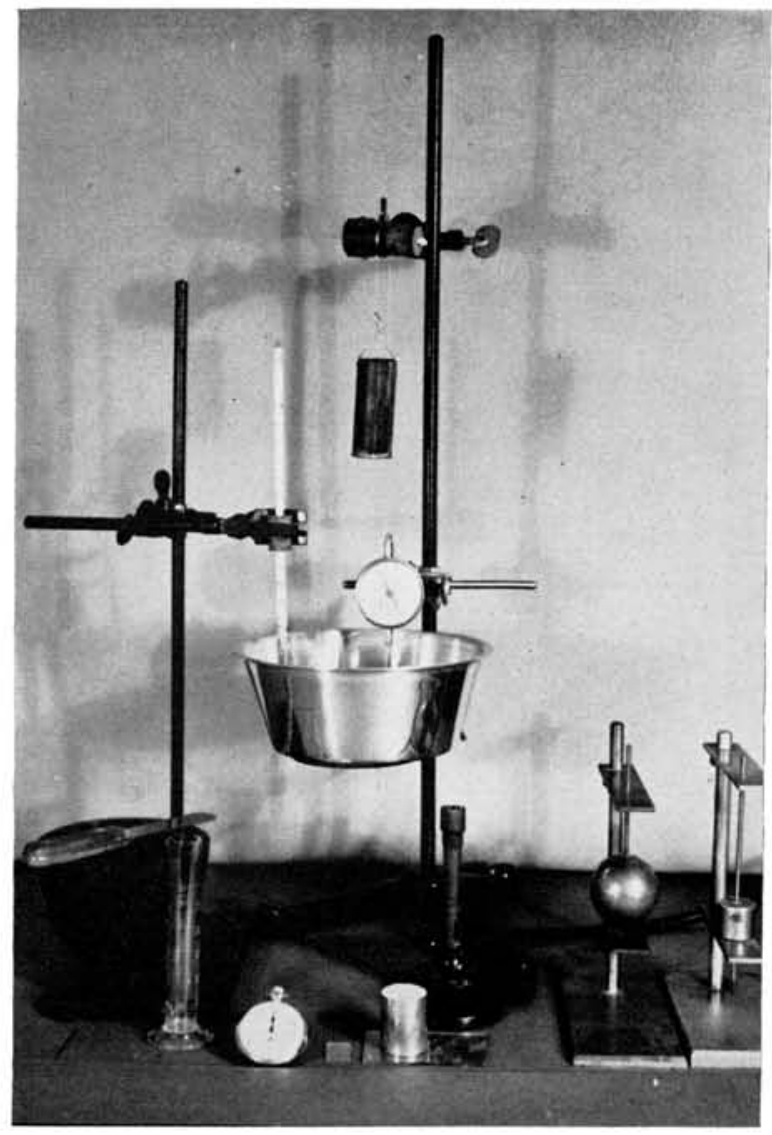

Fig. 1.-Apparatus for measuring hygroscopic expansion.

Some of the trials were carried out in the same way as in Scheu's ${ }^{6 b}$ investigations, where the investment was allowed to set in air before being immersed in the water bath. Other experiments were made with immersion of the specimen in water at different times before setting. The initial set was determined by a Gillmore needle. The water-powder ratio also was varied in order to study how that would affect the expansion. The temperature of the water bath was in most cases kept at $37^{\circ} \mathrm{C}$., but in some it was raised to $50^{\circ} \mathrm{C}$. in order to investigate the effect of the temperature on the expansion. There were also some experiments where two asbestos linings were used instead of 
one. In each experiment, readings were taken at 1-minute intervals in the early stages and then at 5-minute intervals toward the end of the measurement period, which was 60 minutes for each sample.

The following investments were studied:

\section{Name}

Hygroscopic Investment

Gray Investment

Beauty Cast Investment

Cristobalite Investment

\section{Manufacturer}

Ransom and Randolph Company, Toledo, Ohio „Ransom and Randolph Company, Toledo, Ohio Whip-mix Corporation, Louisville, Ky.

Kerr Manufacturing Company, Detroit, Mich.

TABLE I

RANSOM AND RANDOLPH HYGROSCOPIC INVESTMENT

\begin{tabular}{|c|c|c|c|c|c|}
\hline CURVE & $\begin{array}{c}\text { WATER-POW DER } \\
\text { RATIO }\end{array}$ & $\begin{array}{c}\text { TEMP. OF } \\
\text { WATER BATH } \\
\left({ }^{\circ} \text { C. }\right)\end{array}$ & $\begin{array}{c}\text { INITIAL } \\
\text { SEI } \\
\text { (MIN.) }\end{array}$ & $\begin{array}{c}\text { TIME OF } \\
\text { IMMERSION } \\
\text { (MIN.) }\end{array}$ & $\begin{array}{c}\text { MAXIMUM } \\
\text { EXPANSION } \\
(\%)\end{array}$ \\
\hline \multicolumn{6}{|c|}{ ( } \\
\hline 1 & 0.31 & 37 & 16 & immediate & 1.88 \\
\hline $\overrightarrow{2}$ & 0.31 & 37 & 14 & 14 & 1.41 \\
\hline 3 & 0.31 & 37 & 16 & 16 & 1.21 \\
\hline 4 & 0.31 & 37 & 18 & 18 & 1.02 \\
\hline 5 & 0.31 & 37 & 18 & 20 & 0.87 \\
\hline 6 & 0.31 & 37 & 18 & 30 & 0.33 \\
\hline \multicolumn{6}{|l|}{$\mathrm{B}$} \\
\hline 1 & 0.31 & 50 & 17 & 16 & 1.44 \\
\hline 2 & 0.31 & 50 & 16 & 16 & 1.42 \\
\hline 3 & 0.31 & 37 & 16 & 16 & 1.24 \\
\hline 4 & 0.31 & 37 & 16 & 16 & 1.21 \\
\hline \multicolumn{6}{|l|}{$\mathrm{C}$} \\
\hline 1 & 0.31 & 50 & 18 & 18 & 1.21 \\
\hline$\overline{2}$ & 0.31 & 50 & 18 & 18 & 1.12 \\
\hline 3 & 0.31 & 37 & 18 & 18 & 1.04 \\
\hline 4 & 0.31 & 37 & 18 & 18 & 1.02 \\
\hline \multicolumn{6}{|l|}{$\bar{D}$} \\
\hline 1 & 0.31 & 37 & 18 & 14 & 1.84 \\
\hline 2 & 0.31 & 37 & 18 & 14 & 1.77 \\
\hline 3 & 0.31 & 50 & 18 & 14 & 1.76 \\
\hline 4 & 0.31 & 50 & 17 & 14 & 1.74 \\
\hline \multicolumn{6}{|l|}{$\mathrm{E}$} \\
\hline 1 & 0.31 & 37 & 17 & 18 & 1.14 \\
\hline 2 & 0.31 & 37 & 17 & 18 & 1.12 \\
\hline 3 & 0.31 & 37 & 18 & 18 & 1.04 \\
\hline 4 & 0.31 & 37 & 18 & 18 & 1.02 \\
\hline \multicolumn{6}{|l|}{$\mathrm{F}$} \\
\hline 1 & 0.28 & 37 & 15 & immediate & 2.02 \\
\hline$\overline{2}$ & 0.34 & 37 & 19 & immediate & 1.93 \\
\hline 3 & 0.30 & 37 & 16 & immediate & 1.93 \\
\hline 4 & 0.31 & 37 & 18 & 8 & 1.93 \\
\hline 5 & 0.33 & 37 & 19 & immediate & 1.91 \\
\hline 6 & 0.31 & 37 & 17 & immediate & 1.89 \\
\hline 7 & 0.31 & 50 & 16 & immediate & 1.88 \\
\hline 8 & 0.31 & 37 & 16 & 12 & 1.88 \\
\hline 9 & 0.32 & 37 & 18 & immediate & 1.85 \\
\hline 10 & 0.31 & 37 & 16 & immediate & 1.85 \\
\hline 11 & 0.36 & 37 & 20 & immediate & 1.82 \\
\hline
\end{tabular}

EXPERIMENTAL DATA

The results from various test conditions are plotted in graphs representing the total data taken for each condition of test. In each graph, the time in 
minutes is plotted on the base of the graph with the expansion in 1/1000 inch on the left and corresponding percentage on the right. The first six graphs represent results obtained from tests under different conditions on Hygro-

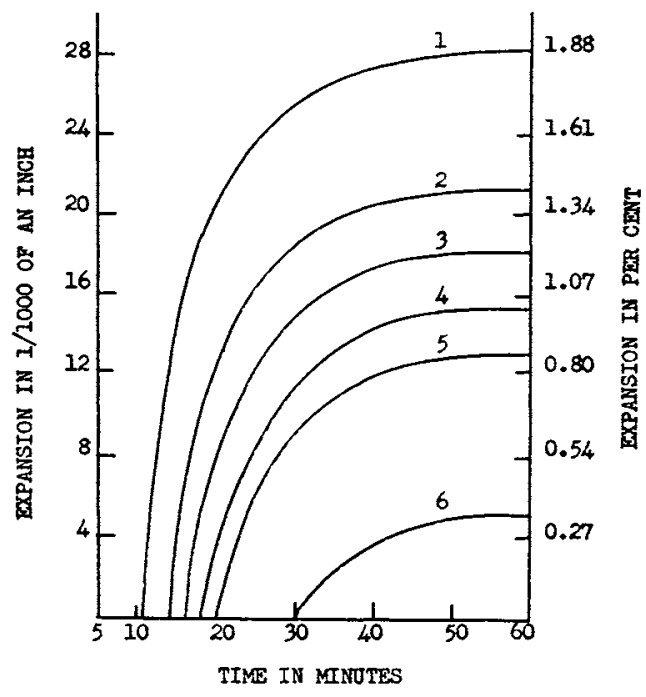

Fig. 2.-Ransom-Randofph Hygroscopic Investment. Effect on expansion of time between mixing and immersion.

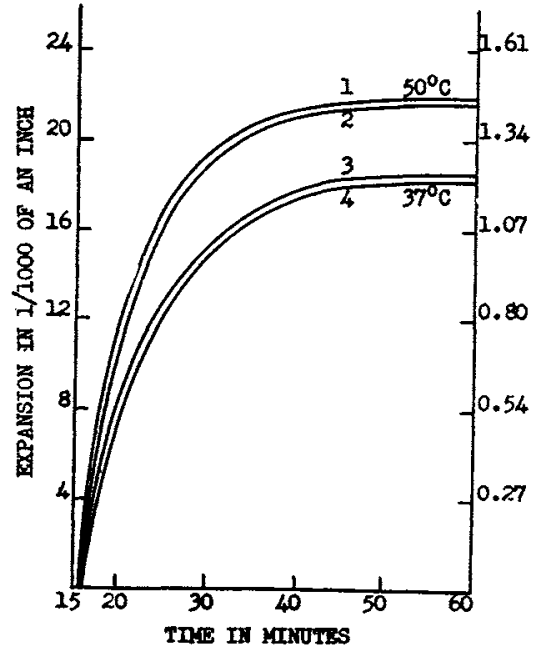

Fig. 3.

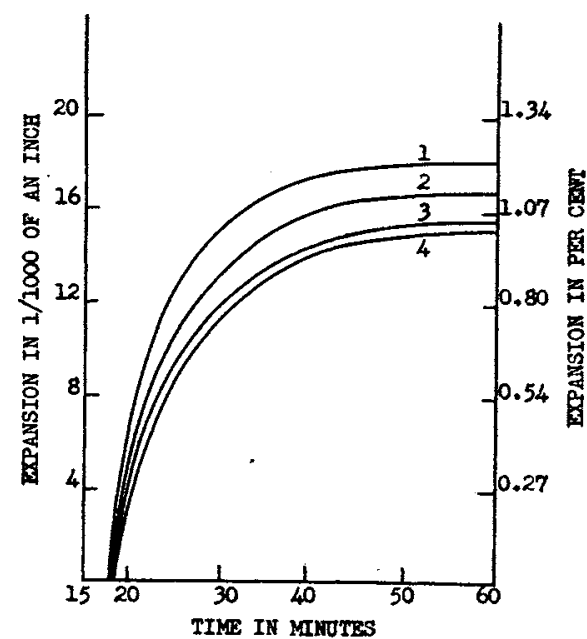

Fig. 4.

Fig. 3.-Ransom-Randolph Hygroscopic Investment. Effect on expansion of temperature of the water bath. Immersed 16 minutes after mixing.

Fig. 4.-Ransom-Randolph Hygroscopic Investment. Effect on expansion of temperature of the water bath. Immersed 18 minutes after mixing.

scopic Investment. A summary of test conditions and the maximum expansion obtained for each test condition is given in Table I which corresponds to data in the graphs of Figs. 2 to 7. 
In Fig. 2, Curve 1 was obtained when immersion in the water bath was made in 2 minutes, or as soon as possible after mixing, and shows the greatest expansion. Although immersed promptly after mixing, the investment did not possess sufficient strength to develop a measurable change in dimension until 11 minutes after mixing. Curves 2, 3, and 4 were obtained when immersion was made at the time for initial set, determined with a Gillmore needle. Curve 2 was obtained when the investment was taken from a newly opened can and had a setting time of 14 minutes. Some days later the setting time was not the same, even though the same powder-water ratio and other test conditions were used. The immersion was made after an initial set of 16 minutes (Curve 3) and the expansion was less. A week later the setting time was 18

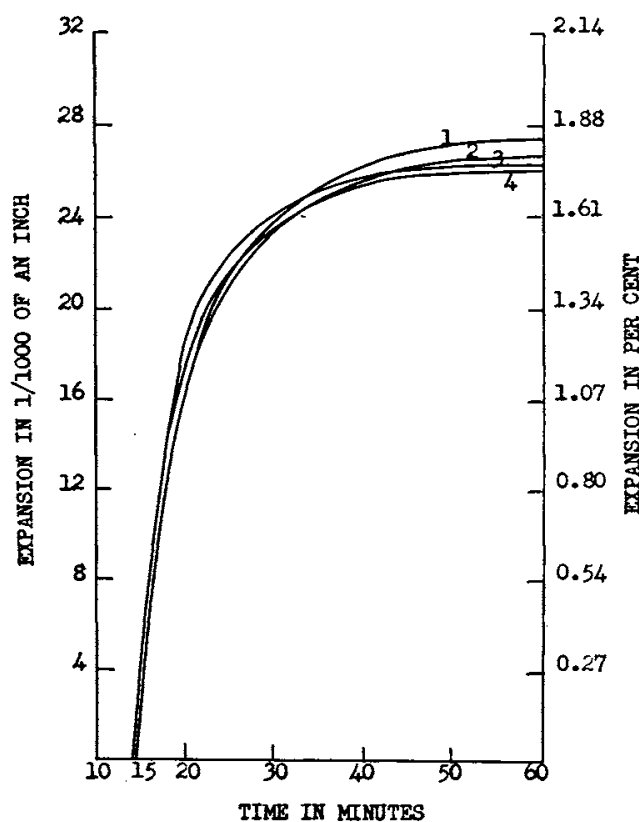

Fig. 5.

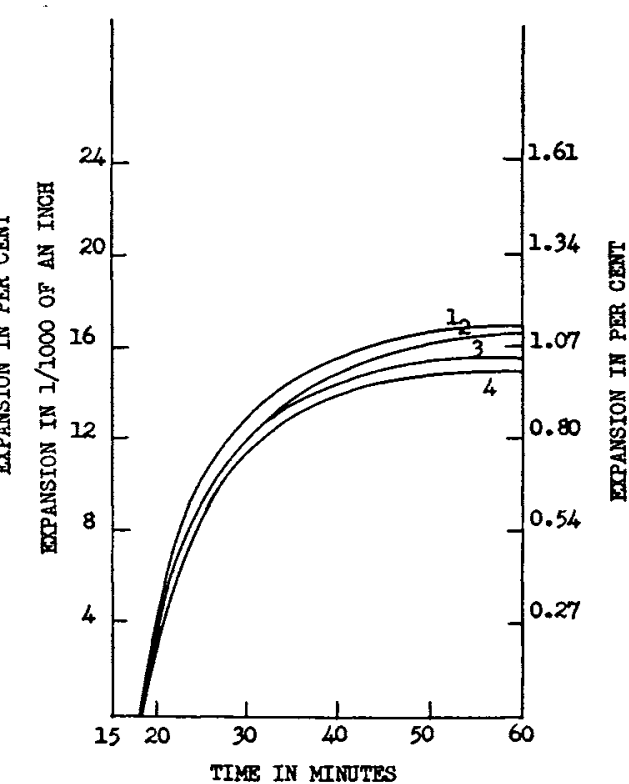

Fig. 6.

Fig. 5.-Ransom-Randolph Hygroscopic Investment. Effect on expansion of temperature of the water bath. Immersed 16 minutes after mixing. linings.

Fig. 6.-Ransom-Randolph Hygroscopic Investment. Effect on expansion of two asbestos

minutes, and the values for expansion are seen in Curve 4 . The change in initial setting time perhaps was due to moisture taken up by the investment from the air. Results shown by Curves 5 and 6 were obtained when immersion was made a certain time after initial set, which was 20 and 30 minutes after mixing. The results in Fig. 2 show that the hygroseopic expansion is greatest when the specimen is immersed immediately after mixing, and the expansion decreases with increased time between mixing and immersion in water.

In Fig. 3 and Table I (B) are given the results obtained when immersion was made at the time of the initial set, which in this case was 16 minutes after 
mixing. Values in Curves 1 and 2 were obtained when the temperature of the water bath was $50^{\circ} \mathrm{C}$, and Curves 3 and 4 represent a water-bath temperature of $37^{\circ} \mathrm{C}$. It is seen that there is a slight increase in expansion $(0.2$ per cent) with increased temperature of the bath.

When immersion was made 18 minutes after mixing (Fig. 4, Table I [C]), which was also the initial setting time for this series of samples, a water bath temperature of $50^{\circ} \mathrm{C}$. gave values shown in Curves 1 and 2. Values in Curves 3 and 4 were obtained when the investment was immersed in water at $37^{\circ} \mathrm{C}$.

In Fig. 5 and Table $I$ (D) are given the values obtained when immersion was made 14 minutes after mixing but 3 to 4 minutes before the initial set. $A$ water-bath temperature of $50^{\circ} \mathrm{C}$. was used to obtain values shown by Curves 1 and 2, with Curves 3 and 4 representing values obtained from a bath of $37^{\circ} \mathrm{C}$. It will be observed that the curves are rather close together and the temperature does not seem to affect the expansion appreciably when the immersion is made before the initial setting time.

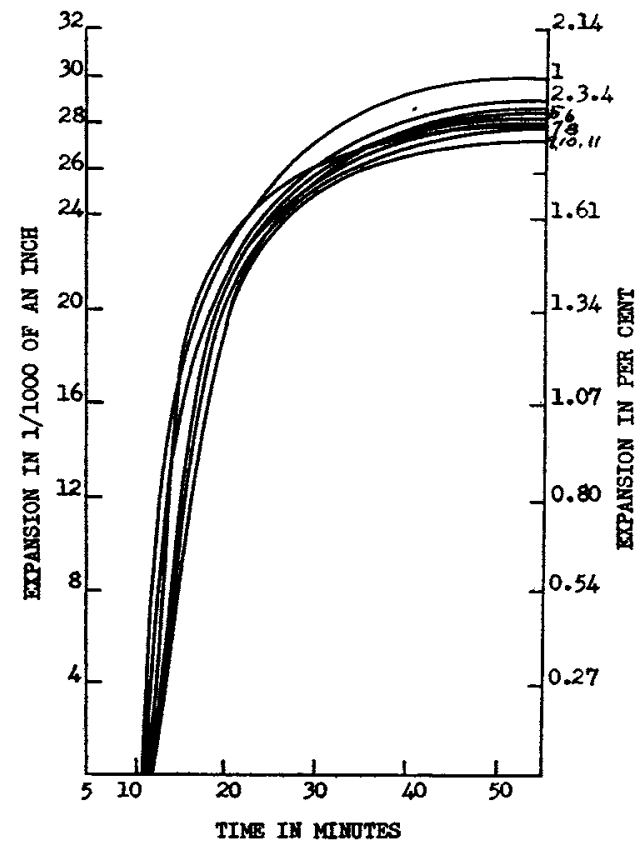

Fig. 7.

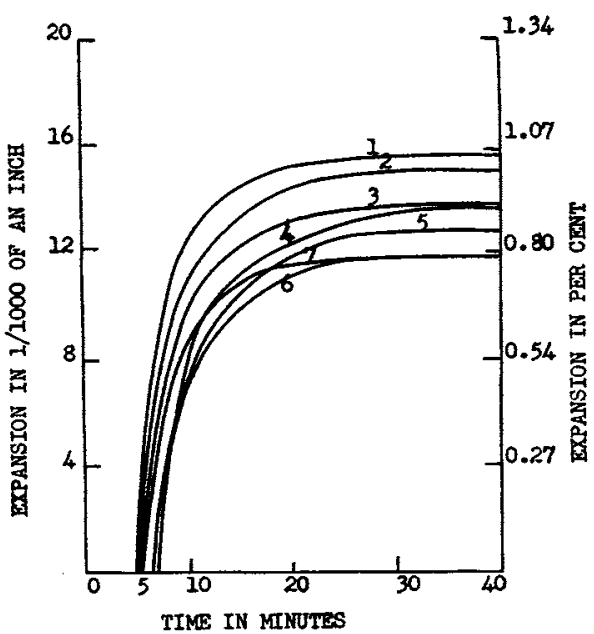

Fig. 8 .

Fig. 7.--Ransom-Randolph Hygroscopic Investment. Fxpansion when immersion is made before initial set with variations in water-powder ratio and in temperature of the water bath.

Fig. 8.- Ransom-Randolph Gray Investment. Expansion of Gray Investment when immersed immediately and after initial set.

The results shown in Fig. 6 and Table $I(E)$ indicate a slight increase in the expansion (0.1 per cent) when two asbestos liners are used (Curves 1 and 2 ) in the ring instead of one. In this series of tests, the specimens were immersed in a $37^{\circ} \mathrm{C}$. water bath at the time of initial set, which was 18 minutes after mixing. 
The curves shown in Fig. 7, with corresponding data in Table I (F), were obtained when immersion was made before the initial set. The experiments were made with the mix in a semifluid consistency when immersed. Results in Curve 1 represent a thick mix with water-powder ratio of 0.28 , while Curve 11 represents a thin mix with water-powder ratio of 0.36 . These two curves indicate a tendency toward increased expansion when a thick mix is used. If Curves 1 and 11 are not considered, the remainder of the curves are within a very narrow range, in spite of variations in water-powder ratio between 0.30 and 0.34 and water bath temperatures between 37 and $50^{\circ} \mathrm{C}$. Even though the test specimens were immersed in the water bath at intervals from 2 to 12 minutes after mixing, almost the same hygroscopic expansion oceurred. As seen from these curves, the variation in expansion for this product is so small as to be of little practical significance when limited variations are made in the water-powder ratio, water-bath temperature, and time of immersion before the initial set. This is thought to be a good quality, since in practice some types of patterns require longer investing times than others.

The data shown in Fig. 8 and Table II represent values obtained when Gray Investment is used. This investment has been designed for use with thermal expansion technics. The expansion is slightly greater when immersion is made immediately after mixing (Curves 1, 2, and 3) than when immersed after the initial set (Curves 4, 5, and 6). The low value shown by Curve 7 may be the result of the confinement of the cover slide during the experiment. The hygroscopic expansion of this investment is rather low and not sufficient for full compensation of the gold shrinkage. In an investment designed for thermal expansion, a low hygroseopic expansion should be considered a good quality; otherwise, the use of wet asbestos liners may be hazardous.

TABLE II

Gray INVESTMENT

\begin{tabular}{c|c|c|c|c|c}
\hline & $\begin{array}{c}\text { WATER- } \\
\text { POWDER } \\
\text { RATIO }\end{array}$ & $\begin{array}{c}\text { TEMP. OF } \\
\text { WATER BATH } \\
\left({ }^{\circ} \text { C. }\right)\end{array}$ & $\begin{array}{c}\text { INITIAL } \\
\text { SET } \\
(\text { MIN. })\end{array}$ & $\begin{array}{c}\text { TIME OF } \\
\text { IMMERSION } \\
(\text { MIN. })\end{array}$ & $\begin{array}{c}\text { MAXIMUM } \\
\text { EXPANSION } \\
(\%)\end{array}$ \\
\hline 1 & 0.29 & 37 & 6 & immediate & 1.04 \\
2 & 0.29 & 37 & 7 & immediate & 1.00 \\
3 & 0.29 & 37 & 6 & immediate & 0.92 \\
4 & 0.29 & 37 & 7 & 7 & 0.90 \\
5 & 0.29 & 37 & 7 & 6 & 0.85 \\
6 & 0.29 & 37 & 6 & immediate & 0.79 \\
7 & 0.29 & 37 & 7 & & 0.79 \\
\hline
\end{tabular}

When Beauty Cast Investment was used, results of tests were as shown in Figs. 9 and 10, Table III (A and B). In Fig. 9, it is seen from Curves 2, 3, 4, and 5 that the expansion decreases as the time between mixing and immersion increases. Results indicated by Curve 1 show that a maximum expansion in this investment may be obtained when the specimen is immersed at a definite time after mixing but before the initial set. In this case, the specimen was immersed 15 minutes after mixing but 3 minutes before initial set. Values in Curve 3 were also obtained when the specimen was immersed after 15 min- 
utes, but in this case the investment had set before immersion. The relatively great hygroscopic expansion represented by Curve 1 corresponds to an observation made by Scheu that some investments show the maximum expansion when immersed at a certain time after mixing but before the initial set has taken place.

TABLE III

Beauty Cast Investment

\begin{tabular}{|c|c|c|c|c|c|}
\hline CURVE & $\begin{array}{l}\text { WATER-POWDER } \\
\text { RATIO }\end{array}$ & $\begin{array}{c}\text { TEMP. OF } \\
\text { WATER BATH } \\
\left({ }^{\circ} \mathrm{C} .\right)\end{array}$ & $\begin{array}{l}\text { INITIAL SET } \\
\text { (MIN.) }\end{array}$ & $\begin{array}{l}\text { TIME OF } \\
\text { IMMERSION } \\
\text { (MIN.) }\end{array}$ & $\begin{array}{c}\text { MAXIMUM } \\
\text { EXPANSION } \\
(\%)\end{array}$ \\
\hline \multicolumn{6}{|l|}{$\bar{A}$} \\
\hline 1 & 0.30 & 37 & 18 & 15 & 2.31 \\
\hline 2 & 0.30 & 37 & 18 & immediate & 2.04 \\
\hline 3 & 0.30 & 37 & 15 & 15 & 1.57 \\
\hline 4 & 0.30 & 37 & 17 & 17 & 1.39 \\
\hline 5 & 0.30 & 37 & 18 & 25 & 0.62 \\
\hline \multicolumn{6}{|l|}{$\mathrm{B}$} \\
\hline 1 & 0.30 & 37 & 18 & 15 & 2.31 \\
\hline$\frac{1}{2}$ & 0.30 & 37 & 17 & 10 & 2.06 \\
\hline 3 & 0.28 & 37 & 15 & immediate & 2.04 \\
\hline 4 & 0.30 & 37 & 18 & immediate & 2.04 \\
\hline$\overline{5}$ & 0.30 & 37 & 17 & immediate & 2.03 \\
\hline 6 & 0.30 & 37 & 17 & 7 & 1.93 \\
\hline 7 & 0.30 & 37 & 17 & 14 & 1.89 \\
\hline 8 & 0.30 & 37 & 18 & immediate & 1.86 \\
\hline 9 & 0.30 & 50 & 17 & immediate & 1.83 \\
\hline 10 & 0.30 & 37 & 17 & immediate & 1.81 \\
\hline 11 & 0.30 & 50 & 17 & immediate & 1.69 \\
\hline 12 & 0.32 & 37 & 18 & immediate & 1.68 \\
\hline
\end{tabular}

The results shown in the curves of Fig. 10 were all obtained when immersion was made before initial set. Curve 1 in Fig. 10 is the same as Curve 1 in Fig. 9, while Curve 2 resulted from a thick mix with water-powder ratio 0.28 and Curve 12 from a thin mix using a water-powder ratio of 0.32 . The expan= sion increases with the thickness of the mix, although the results indicate a lack of uniform results under the same conditions of test. Immersion immediately after mixing when using similar conditions for water-powder ratio and waterbath temperature gave varying results between 1.81 and 2.04 per cent expansion. Although the variations in investing and test conditions were no greater than those that may occur in laboratory practice, the expansion results, shown in Fig. 10, vary between 1.69 and 2.31 per cent.

The values presented in Fig. 11 and Table IV (A) for Cristobalite Investment show that the hygroscopic expansion increases with the thickness of the mix. The water-powder ratio of 0.40 has been used as a standard thickness of the mix (Curve 3). If 0.5 c.c. less water is used to $50 \mathrm{Gm}$. powder (water. powder ratio 0.39 ), the expansion increases 0.08 per cent (Curve 2 ). If another 0.5 c.c. water is withdrawn from the mix (water-powder ratio 0.38 ), the expansion increases 0.23 per cent. If, on the other hand, more water is added to the standard mix, the expansion does not seem to be so readily affected. If 21 c.c. of water is used to $50 \mathrm{Gm}$. powder instead of 20 c.c. (water-powder ratio 0.42 ), the expansion decreases only 0.07 per cent (Curve 4). 


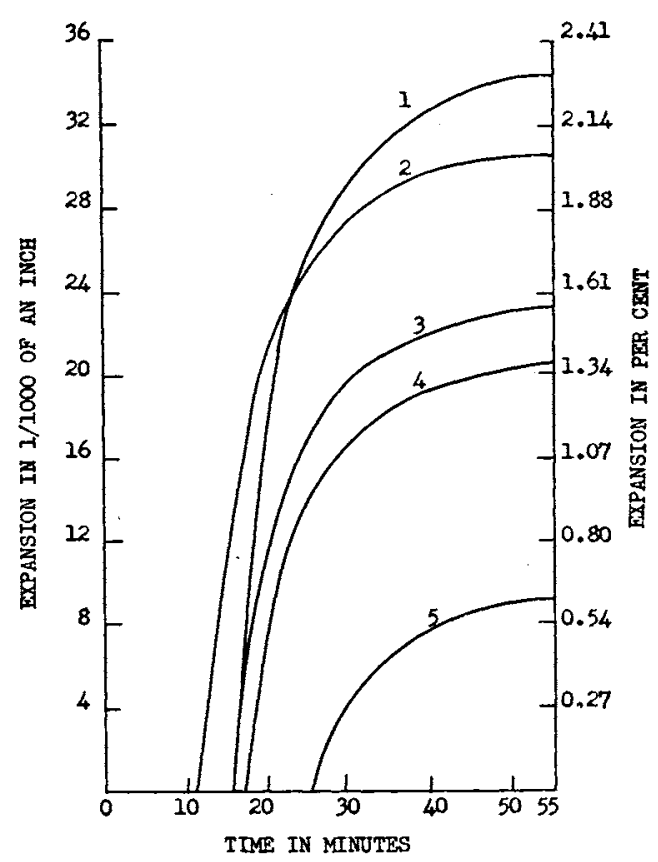

Fig. 9.

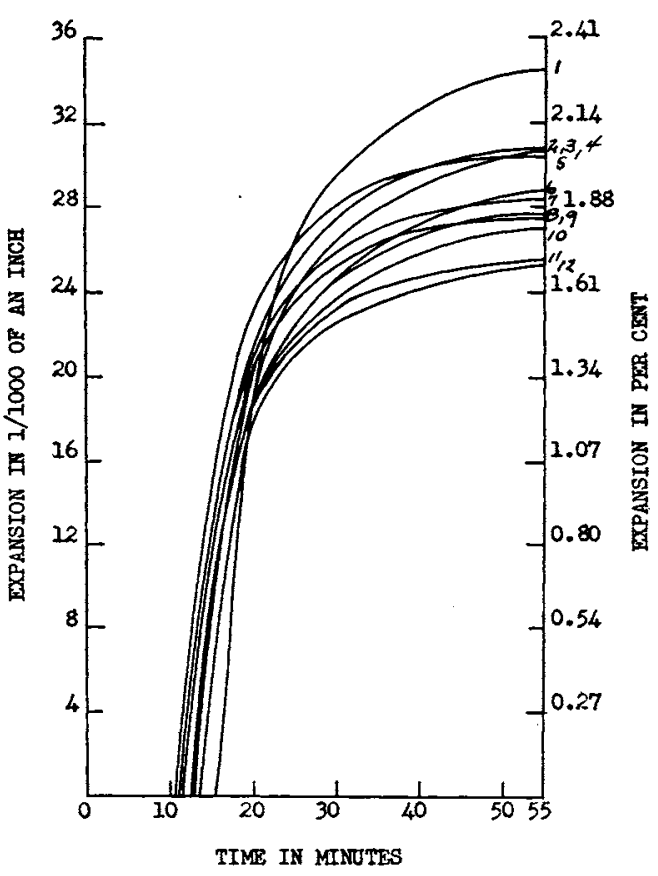

Fig. 10 .

Fig. 9.-Beauty Cast Investment. Effect on expansion of time between mixing and immersion.

Fig. 10.--Beauty Cast Investment. Expansion when immersion is made before initial set with variations in water-powder ratio and in temperature of the water bath.

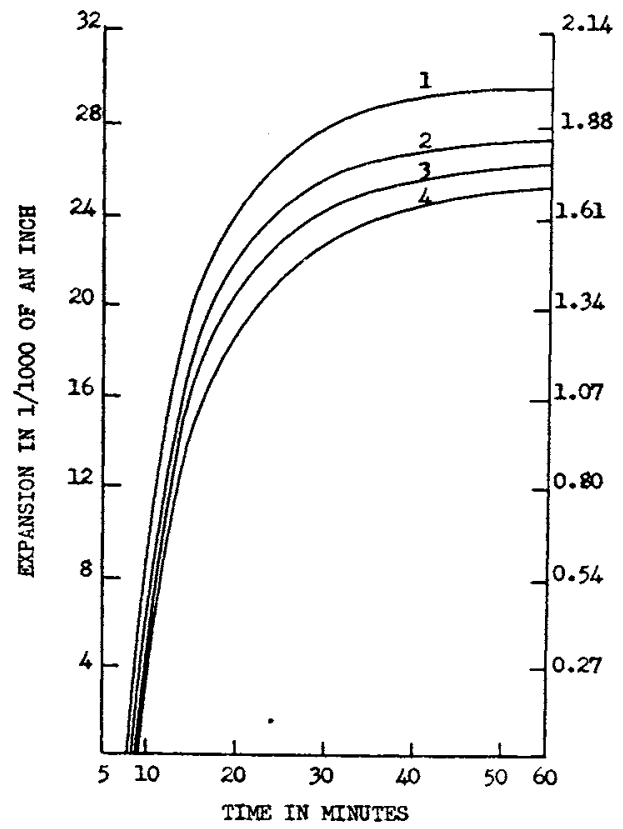

Fig. 11.

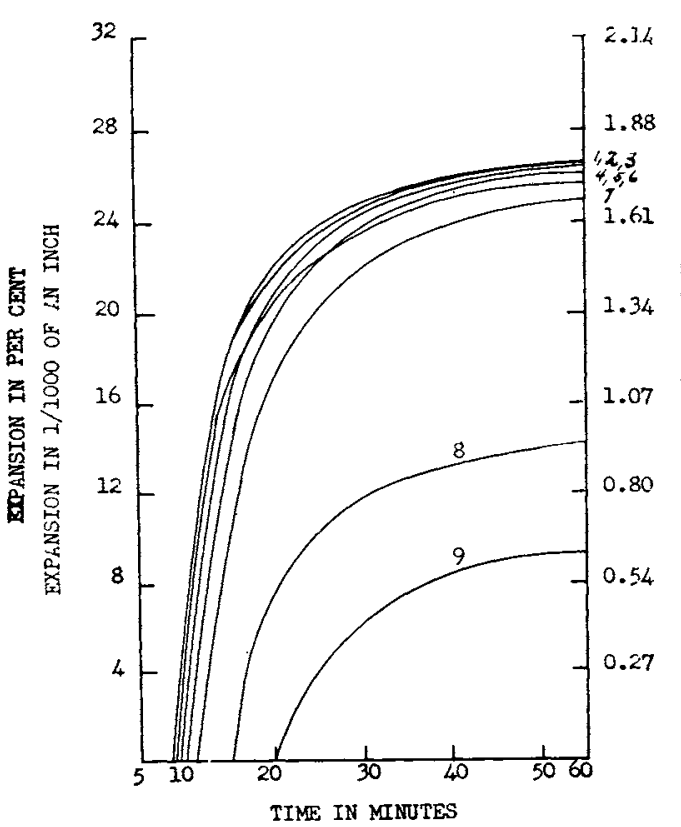

Fig. 12.

Fig. 11.-Cristobalite Investment. Effect on expansion of different water-powder ratios.

Fig. 12.-Cristobalite Investment. Effect on expansion of time between mixing and immersion and of variations of temperature of the water bath. 
It is evident from the curves in Fig. 12 and Table IV (B) that the expansion is greatest when the immersion in the water bath is made between 2 and 12 minutes after mixing. Between these times, the results are uniform, which is a good quality, as in some types of patterns the time necessary for investing is longer than in others. The increased temperature of the bath seems to have $a$ slight effect of increasing the hygroscopic expansion (Curves 1 and 2). If immersion is made after initial set, the hygroseopic expansion decreases with increased time between mixing and immersion (Curves 8 and 9 ).

TABLE IV

Cristobalite Investment

\begin{tabular}{|c|c|c|c|c|c|}
\hline CURVE & $\begin{array}{c}\text { WATER-POWDER } \\
\text { RATIO } \\
\end{array}$ & $\begin{array}{c}\text { TEMP. OF } \\
\text { WATER BATH } \\
\left({ }^{\circ} \mathrm{C} .\right)\end{array}$ & $\begin{array}{l}\text { INITIAL, SET } \\
\text { (MIN.) }\end{array}$ & $\begin{array}{c}\text { TIME OF } \\
\text { IMMERSION } \\
\text { (MIN.) }\end{array}$ & $\begin{array}{c}\text { MAXIMUM } \\
\text { EXPANSION } \\
(\%)\end{array}$ \\
\hline \multicolumn{6}{|l|}{$\mathrm{A}$} \\
\hline 1 & 0.38 & 37 & 13 & immediate & 1.99 \\
\hline 2 & 0.39 & 37 & 14 & immediate & 1.84 \\
\hline 3 & 0.40 & 37 & 15 & immediate & 1.76 \\
\hline 4 & 0.42 & 37 & 16 & immediate & 1.69 \\
\hline \multicolumn{6}{|l|}{$\mathrm{B}$} \\
\hline 1 & 0.40 & 50 & 15 & immediate & 1.77 \\
\hline 2 & 0.40 & 50 & 15 & immediate & 1.77 \\
\hline 3 & 0.40 & 37 & 15 & immediate & 1.76 \\
\hline 4 & 0.40 & 37 & 15 & immediate & 1.73 \\
\hline 5 & 0.40 & 37 & 15 & 8 & 1.72 \\
\hline 6 & 0.40 & 37 & 15 & 12 & 1.71 \\
\hline 7 & 0.40 & 37 & 15 & 10 & 1.67 \\
\hline 8 & 0.40 & 37 & 15 & 15 & 0.95 \\
\hline 9 & 0.40 & 37 & 15 & 20 & 0.63 \\
\hline
\end{tabular}

CONCLUSIONS

1. Hygroscopic expansion decreases with the increased time between mixing and immersion when immersion is made after initial set.

2. When the investment is immersed after initial set, the temperature of the water bath affects the expansion slightly. Higher temperature of the bath gives increased expansion.

3. When the investment is immersed before initial set, the greatest expansion is obtained and the results are most uniform.

4. There is a slight increase of the expansion when two asbestos linings are used instead of one.

5. Hygroscopic expansion of some investments is not great enough for full compensation of the gold shrinkage.

6. The expansion of some investments is more readily modified than others by differences in water-powder ratio and temperature of the water bath.

7. The casting investment designed for hygroscopic expansion technic gives more uniform results than those primarily designed for thermal expansion.

8. The method of choice in hygroscopic expansion technic is to immerse the specimen 2 to 12 minutes after mixing and keep the specimen in the water a.t $37^{\circ} \mathrm{C}$. for 50 minutes. 


\section{REFERENCES}

1. Taggart, W. H.: A New and Accurate Method of Making Gold Inlays, D. Cosmos 49: $1121,1907$.

2. Van Horn, C. S.: Casting: A Review and Commentary, Including a Technique, $D$. Cosmos 52: 873, 1910.

3. Coleman, R. L.: Physieal Properties of Dental Materials, Research Paper No. 32, U. S. Govt. Printing Office, 1928.

4. Skinner, E. W.: Present Status of the Inlay Casting Technie, Ill. D. J. 15: 499, 1946.

5. Hollenback, G. M.: Precision Gold Inlays Made by a Simple Technique, J. A. D. A. 30: $99,1943$.

6a. Scheu, C. H.: A New Precision Casting Technic, J. A. D. A. 19: 630, 1933.

6b. Scheu, C. H.: Precision Casting Utilizing the Hygroscopic Action of Plaster in Investment in Making Expanded Molds, J. A. D. A. 20: 1205, 1933.

7. Wilson, G. H.: Manual of Prosthetic Dentistry, Philadelphia, 1920, Lea \& Febiger, p. 78 .

8. Docking, H. R.: The Hygroscopic Setting Expansion of Dental Casting Investments, Parts I, II, and III, Australia J. D. 52: 6, 160, and 320, 1948; Part IV, 53: 261, 1949.

9. Degni, F.: The Hygroseopic Expansion of Dental Investments, Thesis, Northwestern University Dental School, 1946.

10. Skinner, E. W.: The Science of Dental Materials, ed. 3, Philadelphia, 1947, W. B. Saunders Company.

11. Coleman, R. L.: Physical Properties of Dental Materials, D. Cosmos 68: 743, 1926.

12. Watts, C. H.: A Study of Investment Expansions Required for Gold Inlay Castings, read before Dental Materials Group, I. A. D. R., Kansas City, Mo., 1948.

13. Skinner, E. W.: The Role of Investment Setting Expansion in Gold Compensation Casting Technique, D. Cosmos 75: 1009, 1933. 